\title{
Lung cancer chemoprevention: current status and future directions
}

\author{
Jenny T. Mao • Ravi Durvasula
}

Published online: 1 February 2012

(C) Springer Science+Business Media, LLC 2012

\begin{abstract}
Lung cancer is the leading cause of cancer death in the world. In the United States, lung cancer causes more death per annum than colorectal, breast, and prostate cancers combined. While smoking prevention and cessation are essential strategies against lung cancer, they are often ineffective, and former smokers remain at lower, yet persistent risks. The magnitude of the tobacco epidemic and burden of lung cancer will continue to escalate globally, underscoring the importance of advancing chemoprevention research. Recently, exciting results from phase $2 \mathrm{~b}$ randomized control trials are beginning to emerge. Advancements in understanding clinical tumor biology, diagnostic technology, and bioinformatics will continue to propel significant progress in the field. This update will provide a general overview of the background and rationale for lung cancer chemoprevention, review important results from historical trials, summarize key findings from recently completed studies, and discuss ongoing clinical trials and future directions for lung cancer chemoprevention.
\end{abstract}

Keywords Lung cancer - Chemoprevention - Carotinoids . Retinoids · Vitamin E · Selenium · Budesonide · Arachidonic acid $\cdot$ Ki-67 $\cdot$ Bronchial dysplasia $\cdot$ Surrogate end point biomarker - Cyclooxygenase-2 inhibitors · Celecoxib . $\mathrm{PGE}_{2} \cdot$ Aspirin $\cdot$ Iloprost $\cdot$ Myoinositol $\cdot$ PPAR-gamma agonists $\cdot$ Tea extracts $\cdot$ Isothiocyanates .

Personalized approach

J. T. Mao $(\square)$

Pulmonary and Critical Care Section,

New Mexico VA Health Care System/University of New Mexico, Albuquerque, NM, USA

e-mail: jenny.mao@va.gov

R. Durvasula

Center for Global Health, Division of Infectious Disease,

New Mexico VA Health Care System/University of New Mexico,

Albuquerque, NM, USA

\section{Introduction}

Over the past century, advancements in medicine, technology, and health care have led to dramatic epidemiologic transition as a country evolves through the process of modernization. Whereas infections and nutritional deficiencies used to account for the leading causes of premature death and morbidity, with the advent of antimicrobials and improvement of nutrition and health care, these causes are increasingly being replaced by chronic, noncommunicable diseases, including cancer. Globally, known risk factors for chronic diseases have dramatically increased, including tobacco consumption, changing diets, level of physical activity, and environmental and air pollution. Among these risk factors, tobacco use is the single most important preventable risk to human health and an important cause of premature death worldwide [1]. Smoking causes approximately $90 \%$ of lung cancer, the leading cause of cancer death in the world.

In spite of significant advancements in anti-cancer therapy, lung cancer continues to account for the majority of cancerrelated deaths in the world $[2,3]$. The high mortality is primarily due to the fact that the majority of the cases are diagnosed at a late invasive stage when curative treatment is no longer possible. Whereas smoking prevention and cessation remain essential in the overall strategy for lung cancer prevention, these approaches have notable limitations. Even when smoking cessation is successful, former-smokers continue to be at significant risk. Today at least half of all new lung cancers are diagnosed in former smokers [4-6]. Such revelations have led to intensified research in chemoprevention, which entails the use of an agent to impede the carcinogenic process and prevent cancer from developing in individuals at increased risk. Chemoprevention focuses on biological changes associated with the development and early progression of cancer. In contrast to chemotherapy, chemoprevention aims to impede the carcinogenic processes by targeting molecular 
pathways that drive cancerization, thereby preventing the development of invasive cancer. Such an approach provides a powerful platform to advance scientific understanding of tumor biology, from which safe and highly efficacious interventions can be derived.

First coined by Sporn and colleagues [7], chemoprevention is defined as "the use of specific natural or synthetic chemical agents to reverse, suppress, or prevent carcinogenic progression to invasive cancer." Since that time the potential of chemoprevention in reducing mortality risk has been realized in common epithelial cancer; the best example is the use of tamoxifen for breast cancer. Positive phase 3 trial findings have been demonstrated in breast, colon, and prostate cancers [8-11]. Results from phase 3 lung cancer chemoprevention trials over the past two decades, however, had been disappointing. These include the Alpha-Tocopherol, Beta-Carotene (ATBC) trial, Carotene and Retinol Efficacy Trial (CARET), Lung Intergroup Trial (LIT) using 13-cis retinoic acid [12-15], the EUROSCAN trial using retinyl palmitate and/or N-acetylcysteine [16], the Linxian study using four different combinations of vitamin and minerals [17], and a recent randomized controlled trial (RCT) using selenium [18] (Table 1).

Comparatively, the lungs and bronchi make up a far more intricate organ system comprised of complex anatomic architecture, tissues, and cell types that function not only for gas exchange, but serve as first line of defense against inhaled pathogens and noxious stimuli and mediate and regulate inflammatory responses, as well as immune functions. The respiratory tree is continually and directly exposed to high levels and vast numbers of harmful matters. As such, it is not surprising that chemoprevention of bronchogenic carcinomas presents far greater challenges then malignancies of other solid organs. Nonetheless, many of the principles and strategies that have proven effective in chemoprevention of other common malignancies apply to lung cancer.

\section{Lung carcinogenesis and biomarkers}

Lung tumorigenesis results from lengthy, complex interactions between genetic predisposition and environmental influences. Malignant transformation begins with initiation, in which exposure of the respiratory epithelium to carcinogens leads to mutations in oncogenes, tumor suppressor genes, and DNA repair genes. While the human body has tremendous capacity to compensate for the damages caused by these harmful matters, continued exposures fuel the process of promotion, which is orchestrated by a series of genetic and epigenetic alterations in respiratory epithelial cells, aberrant interactions with other cell types, and imbalances of the network of biologic response modifiers, including cytokines, growth factors, and eicosanoids in the lung microenvironment. These alterations manifest as malignant phenotypic changes characterized by resistance to apoptosis, uncontrolled cellular proliferation, enhancement of angiogenesis, suppression of anti-tumor immunity, and increased epithelial mesenchymal transition. Collectively these mechanisms facilitate the driving force of cancerization, which is a multi-step process marked by progressions of premalignant changes in the respiratory epithelium [19-21].

According to the field carcinogenesis theory, exposure of the entire respiratory epithelium can lead to malignant transformation at multiple, independent sites. With sufficient genetic
Table 1 Phase 3 lung cancer chemoprevention trials

\begin{tabular}{llll}
\hline Study & Agents & $1^{0}$ End point & Outcome \\
\hline ATBC 1994 & $\beta$-carotene/vitamin E & Lung cancer & $(-)$ \\
CARET 1996 & $\beta$-carotene/retinal & Lung cancer & $(-)$ \\
NCI Intergroup 2000 & 13cRA & Second primaries & $(-)$ \\
EUROSCAN 2000 & Retinol/NAC & Second primaries & $(-)$ \\
Linxian 2006 & 4 diff combinations of vitamins/mineral & Lung cancer mortality & $(-)$ \\
MDACC 2010 & Selenium & Second primaries & $(-)$ \\
Results of large-scale RCT-based study for lung cancer chemoprevention & \\
UK Physicians' & Aspirin & Lung cancer & $(-)$ \\
Health Study 1988 & Aspirin & Lung cancer & $(-)$ \\
US Physicians' & & & $(-)$ \\
Health Study 1988 & & Lung cancer & \\
US Physicians' & $\beta$-carotene & & $(-)$ \\
Health Study 1996 & & Lung cancer & $(+)$ \\
Health Study 2005 & Aspirin & Lung cancer mortality & ( \\
$\begin{array}{l}\text { Meta analysis } \\
\text { of 8 RCT 2011 }\end{array}$ & Aspirin & & \\
\hline
\end{tabular}


instability and promotion, some of these sites may eventually evolve into cancer. Furthermore, these aberrant molecular and cellular changes can be identified in respiratory secretions, exfoliated cells, tissue, and blood samples using molecular and biochemical techniques, the modulations of which may be useful as surrogate biomarkers of response to anti-neoplastic agents. As our understanding of lung cancer biology and diagnostic technologies continues to advance, more refined risk assessment with targeted therapeutic approach toward personalized chemopreventive strategy to maximize efficacy, as well as favorable risk-benefit ratios, is becoming increasingly tangible.

\section{Past experiences and challenges: productive failure is the key to success}

Most of the historic phase 3 lung cancer chemoprevention trials were launched based on findings from epidemiologic, observational studies. While disappointing, important information and lessons learned from these studies continue to shape and improve the designs of subsequent trials. Several plausible explanations have been derived to account for decades of failed attempts to translate epidemiologic and preclinical clues into successful chemopreventive approaches for lung cancer.

Inaccurate interpretations of epidemiologic findings

The observation that diets high in carotenoids-rich fruits and vegetables are associated with reduced lung cancer risks led to several large-scale, phase 3, randomized, placebo-controlled trials using high-dose beta-carotene or retinoids [12-15]. Unfortunately, these agents actually increased the risk of lung cancer in active smokers while showing a potential benefit in former and never smokers. Such revelations have important public health implications. Before such definitive findings, supplementations with high-dose carotinoids and retinoids were becoming common practices for disease prevention, which would have substantially contributed to much higher mortality risk in active smokers. Experience from these studies also illustrated the formidable challenges in reversing carcinogenic process and premalignancy in the setting of continued tobacco exposure [22]. Because chemopreventive agents may exert differential effects in current and former smokers, many contemporary trials either exclude current smokers or analyze these subjects separately [23].

\section{Limitations of preclinical models}

Presently, the discovery, selection, and development of promising agents for lung cancer chemoprevention trials follow five general approaches: 1) identification of suggestive clues and molecular targets involved in lung carcinogenesis from observational, case-control, and/or preclinical studies; 2) in vitro evaluation of the effects of drugs or targeted agents on cancer or pre-malignant cell biology; 3) in vivo preclinical animal models of lung carcinogenesis or xenografts of human lung cancer; 4) phase 1 and 2 clinical trials using surrogate end point biomarkers (SEBM) in humans; and 5) phase 3 RCT using cancer incidence as end points.

In vitro preclinical models are often uni-dimensional, unable to account for the complex interactions between varying cell types that normally occur in vivo. They are frequently limited by in vitro artifacts, thus requiring higher than physiologic relevant doses to achieve efficacy [24]. They also cannot completely simulate the complex, in vivo issues associated with metabolism and bioavailability. Preclinical mouse models are often inadequate, given tremendous biological, interspecies variations, and the inability of mouse model to account for the heterogeneity of human lung tumor biology. As such, efficacy in murine models frequently fails to translate successfully into human studies. For example, a number of preclinical studies have demonstrated that corticosteroids, either administered systemically or by inhalation, can decrease chemical carcinogen-induced pulmonary adenoma formation in mice [25], but human trials have only yielded negative results [26].

In addition to the aforementioned issues, several formidable obstacles stand in the way of progress for successful translations of promising chemopreventive agents. Even in high-risk groups such as heavy smokers, the actual incidence of lung cancer is still quite low-approximately $10 \%-15 \%$ [4]. In a chronic disease with such a complex biology that takes decades of carcinogenic exposure and molecular cellular damage for the malignant phenotype to manifest clinically, timely evaluation of promising chemopreventive agents and completion of trials is impossible to achieve if the primary end point is cancer incidence. Such an end point requires huge sample sizes, lengthy follow-up, and tremendous resources. To this end, intermediate end points have long been used in early-phase lung chemoprevention trials to access efficacy.

\section{Lack of validated SEBM}

To further complicate the matter, there are no validated SEBM that can reliably predict lung cancer incidence at present. Even the use of bronchial pre-neoplastic lesions as SEBM is fraught with controversies, including the potential of spontaneous reversal of pre-neoplasia and more recently, issues pertaining to sampling with serial bronchial biopsies of the same site that may completely remove the preneoplastic lesions at baseline bronchoscopy [26]. Conceivably if the preneoplastic lesions are completely removed at baseline, as the biopsy sites wound heals, the mucosa will be replaced by relatively normal tissue. Because the development of preneoplastic change is expected to be a lengthy process, it is highly probable that histopathology 
from serial biopsy of the same bronchial site after 6 months may not accurately reflect the driving force of cancerization in the lung milieu. Such notion is consistent with the fact that the placebo groups in many phase 2 lung cancer chemoprevention trials also showed histopathologic improvement post treatment $[26,27 \cdot]$. In view of all the caveats associated with repeated sampling of the bronchial epithelium, it is likely that only large changes in the resolution of bronchial pre-neoplasia may provide sufficient evidence to continue the development of the preventive agent. Further limitation with bronchial histopathology is the fact that bronchial pre-neoplasias are precursors of squamous cell carcinoma, which is no longer the most common NSCLC cell type. As such, the utility of bronchial histopathology as the primary SEBM for lung cancer chemoprevention trials has recently been challenged.

In addition to modulation of histopathology, many chemopreventive trials have used markers causally linked to lung carcinogenesis as SEBM, including the assessment of Ki-67. $\mathrm{Ki}-67$ is a proliferation marker expressed in all phases of the cell cycle except in resting cells [28]. Elevated Ki-67 LI has been reported to be a unfavorable prognostic factor in NSCLC [29]. Because abnormal epithelial proliferation is a hallmark of tumorigenesis and increased Ki-67 expression has been seen in bronchial biopsies where preneoplastic changes are lacking [30], measuring Ki-67 LI in bronchial tissues as a SEBM for a chemopreventive agent with antiproliferative properties may circumvent, to some extent, the potential problems associated with mechanical removal. In a three-arm, double-blind, placebo-controlled RCT among former smokers to examine the effects of a 3-month treatment of 9-cis-retinoic acid (RA), 13-cis-RA, and $\alpha$-tocopherol, or placebo, both treatments were associated with a significant reduction of bronchial Ki-67 LI, a secondary end point of the study [31].

NSCLC can arise centrally in the proximal bronchial epithelium (predominantly squamous cell carcinoma) or peripherally in the distal bronchoalveolar respiratory epithelium (predominantly adenocarcinoma). Most published, randomized, double-blind, placebo-controlled phase $2 \mathrm{~b}$ lung cancer chemoprevention trials have focused on evaluating SEBM on the central bronchi. The phase $2 \mathrm{~b}$ study with budesonide was the first published study to use both low-dose chest CT scans with fluorescence bronchoscopy for SEBM assessment. The study showed a small but statistically significant decrease in the proportion of CT-detected nodules in the budesonidetreated group [26], leading to an RCT with budesonide using serial chest CT for primary end point assessment in patients with CT-detected high-risk lung nodules [32].

Defining favorable risk-benefit ratio of the chemopreventive agent

Because the intent of chemoprevention is to prevent a disease from developing in high-risk individuals that are still relatively healthy, tolerance of risks associated with such an intervention must be kept to a minimum, in contrast to chemotherapy. For example, the chemoprevention field suffered an enormous blow from the well-publicized cardiovascular $(\mathrm{CV})$ risk associated with cycolooxygenase-2 (COX-2) inhibitors and other NSAIDs [33, 34]. Although the increase in CV risk associated with COX-2 inhibitors seems to occur mainly in those individuals with elevated baseline $\mathrm{CV}$ risk factors [35], the general enthusiasm for COX-2 inhibitors for chemoprevention has nonetheless been severely dampened. These types of concerns also contribute to the conduct of studies with marginally active compounds given at suboptimal, pharmacologically ineffectual doses.

The difficulty with recruitment and retention of high-risk human subjects

As mundane the issues may seem, no clinical studies will ever come to fruition without timely recruitment and retention of suitable human subjects to allow accurate end point assessment [36]. This is an important aspect of trial design and grant proposal that is often overlooked, lacking appropriate attention and funding for implementation. Most phase 2 RCT for lung cancer chemoprevention entail multiple layers of screening, diagnostic evaluation, treatment, and follow-up, requiring high level of coordination between and time investment from both the investigative team and subjects to successfully complete the trials.

A lack of personalized approach to lung cancer prevention

In view of the heterogeneity of human biology, no drug is anticipated to exert the same effects on every individual. Such a realization has given rise to the concept of personalized medicine, which is based on identifying the molecular characteristics of an individual that will maximize the probability of a favorable therapeutic response to a medication. Application of personalized approach in lung cancer chemoprevention has lagged behind targeted therapy for lung cancer and chemoprevention of other common epithelial cancers.

\section{Encouraging new findings}

After decades of hard work and disappointments, positive primary end point findings from phase $2 \mathrm{~b}$ RCT are emerging. All of the interventions in some way targeted the arachidonic acid (AA) metabolic pathways. Two of these trials targeted the COX-2 pathway using a specific inhibitor celecoxib [27•, 37•]; the other used a prostacyclin analog iloprost. One of the celecoxib study involved exclusively former smokers [27•], the other two included both former and current smokers $[37 \bullet, 38 \bullet$. 


\section{RCT with celecoxib}

Ample preclinical data suggest that the COX-2/prostaglandin $\mathrm{E}_{2}\left(\mathrm{PGE}_{2}\right)$ signaling pathway plays a pivotal role in conferring the malignant phenotype [39]. Produced primarily by the action of COX on the AA liberated from membrane phospholipids, overproduction of $\mathrm{PGE}_{2}$, which is predominantly generated by up-regulation of $\mathrm{COX}-2$, is associated with a variety of well-established carcinogenic mechanisms [40-43]. COX-2 expression has also been shown to be a poor prognostic indicator in non-small cell lung cancer (NSCLC) [44]. In animal models, inhibition of COX-2 and PGE2 synthesis suppresses lung tumorigenesis $[45,46]$. These data support the anti-neoplastic effect of COX-2 inhibitors and provide the rationale for evaluating their potential as chemoprevention agents for bronchogenic carcinoma.

The first RCT with celecoxib was published by Kim and colleagues in 2010 [37•]. Current or former smokers with at least a 20 pack-year (pack-year $=$ number of packs of cigarettes per day times number of years smoked) smoking history were randomized into one of four treatment arms (3-month intervals of celecoxib then placebo, celecoxib then celecoxib, placebo then celecoxib, or placebo then placebo) and underwent bronchoscopies with biopsies at baseline, 3 months, and 6 months. Celecoxib was initially administered orally at $200 \mathrm{mg}$ twice daily and the protocol subsequently increased the dose to $400 \mathrm{mg}$ twice daily. The 204 patients randomized were primarily current smokers (79.4\%). The primary end point was modulation of bronchial Ki-67 expression (a cellular proliferation maker) from baseline to 3 months by celecoxib. High-dose celecoxib significantly decreased Ki-67 labeling in former smokers and current smokers compared with placebo, after adjusting for metaplasia and smoking status $(P=0.02)$, with stronger reduction of Ki-67 observed in former smokers.

Results from the second RCT with celecoxib were recently published by our group [27•]. In a phase $2 \mathrm{a}$ single-arm trial of celecoxib for lung cancer prevention in active smokers, we showed that celecoxib downregulated $\mathrm{PGE}_{2}$ and interleukin 10 (IL-10) production in alveolar macrophages from active smokers [47], and 6 months of celecoxib treatment significantly downregulated Ki-67 in bronchial epithelial tissue obtained from 20 heavy smokers [48]. These promising results were followed up with a phase $2 \mathrm{~b}$ RCT of celecoxib for lung cancer prevention in former smokers. Former smokers (age $\geq 45, \geq 30$ pack-years of smoking, $\geq 1$ year of sustained abstinence from smoking) were recruited and randomized into two arms (6 months of celecoxib then placebo, 6 months of placebo then celecoxib). Oral celecoxib at $400 \mathrm{mg}$ twice daily was administered. The primary end point was bronchial Ki-67 labeling index (Ki-67 LI) after 6 months of treatment. Of 137 randomized subjects,
101 completed both baseline and 6-month bronchoscopies and were evaluable for the primary end point analysis (52 placebo, 49 celecoxib). Celecoxib significantly decreased Ki$67 \mathrm{LI}$ by an average of $34 \%$, whereas placebo increased Ki-67 LI by an average of $3.8 \%(P=0.04 ; t$ test $)$. The beneficial effect on $\mathrm{Ki}-67 \mathrm{LI}$ was even greater in the celecoxib arm (versus placebo) in a mixed-effects analysis $(P=0.0006)$.

Celecoxib did not have significant effect on histopathology outcomes, although there is a trend favoring celecoxib in maximum histopathology score. Additionally, celecoxib significantly reduced plasma c-reactive protein, interleukin6 mRNA and protein and increased 15(S)-hydroxy-eicosatetraenoic acid (15-HETE) levels in bronchoalveolar lavage (BAL) samples. Furthermore, the baseline ratio of COX-2 to 15-hydroxyprostaglandin dehydrogenase (15-PGDH) mRNA in BAL cells was a significant predictive marker of Ki-67 response to celecoxib $(P=0.002)$. The balance of COX-2 and 15-PGDH determines the ultimate level of $\mathrm{PGE}_{2}$, which likely contributes to the driving force of cancerization in the lung microenvironment; such a balance has been suggested to play a role in the responsiveness of an individual to COX-2 inhibition [49]. Findings from our trial not only confirm the antiproliferative effects of high-dose celecoxib on the bronchial epithelium, indicating the importance of appropriate dosing to achieve antineoplastic effects, but also provide additional evidence for simultaneous, favorable modulations of a number of secondary SEBM. Collectively, these findings reflect the efficacy of COX-2 inhibition on the driving force of cancerization in the lung microenvironment.

This study also incorporated low-dose helical CT for baseline screening and secondary end point assessment at 12 months, in 76 participants who crossed over to the other study arm at 6 months (all of whom had received 6 months of celecoxib at the end of a 12-month treatment period). Hard on the heels of the definitive randomized controlled National Lung Screening Trial (NLST) showing that screening high-risk current or former smokers with $\mathrm{CT}$ scans reduced lung-cancer mortality by $20 \%$, we found that the decreases in Ki-67 LI correlated with a reduction and/or resolution of lung nodules on $\mathrm{CT}$ in our participants. We acknowledge the diagnostic limitation of $\mathrm{CT}$ scans for peripheral precursor lesions in the lungs, the noncomparative nature of our $\mathrm{CT}$ data, and the fact that a recent RCT of budesonide with a primary end point assessed by CT did not show improvement [50]. Nonetheless, our findings suggest that oral celecoxib is biologically active in the respiratory epithelium both centrally and peripherally. The earlier budesonide trial did not report any such correlative results. This is the first report providing evidence that a systemically administered agent may be capable of globally impeding the driving force of cancerization in the lungs, beyond the central airways. 


\section{RCT with Iloprost}

Another approach for targeting the arachidonic acid pathway was conducted by Keith and colleagues [38•] using a prostacyclin $\left(\mathrm{PGI}_{2}\right)$ analogue. $\mathrm{PGI}_{2}$ is a metabolite of $\mathrm{PGH}_{2}$ (derived from AA by the action of COX) with anti-inflammatory, antiproliferative, and potent anti-metastatic properties. Human lung cancer studies have shown that prostacyclin synthase expression is low in most lung cancers and low expression is associated with a worse outcome [51, 52]. Preclinical studies in transgenic mice with selective pulmonary prostacyclin synthase overexpression showed significantly reduced lung tumor multiplicity and incidence in response to either chemical carcinogens or exposure to tobacco smoke [53]. Iloprost, a long-acting oral prostacyclin analog, also inhibits lung tumorigenesis in wild-type mice. Based on these findings, the investigators launched a multi-centered RCT sponsored by the NCI and Lung Cancer Specialized Program of Research Excellence (SPORE) consortium. The primary end point for the trial is endobronchial histopathology, and heavy former and current smokers with sputum atypia were randomized, undergone fluorescence bronchoscopy performed at study entry and after 6 months of treatment with oral iloprost. These patients were required to have sputum atypia and thus were at a higher risk for central bronchial preneoplastic lesions than were patients of the celecoxib trials, who were not so required.

The accrual goal of 152 subjects was reached and 125 completed both bronchoscopies (60/75 iloprost, 65/77 placebo). Within each subject, the results were calculated by using the average score of all biopsies (Avg), the worst biopsy score (Max), and the dysplasia index (DI). Change in Avg was the primary end point, evaluated in all subjects, as well as in current and former smokers. Baseline histology was significantly worse for current smokers than former smokers. When compared with placebo, former smokers receiving oral iloprost exhibited a significantly greater improvement in Avg ( 0.41 units better, $P=0.010$ ), in $\operatorname{Max}$ ( 1.10 units better, $P=$ $0.002)$, and in DI $(12.45 \%, P=0.006)$. No histologic improvement occurred in current smokers. Ki-67 was a secondary end point of this trial and was slightly, non-significantly reduced in the airways of former smokers of the iloprost arm, further reinforcing the importance of smoking status in lung cancer prevention.

\section{Ongoing RCTs in lung cancer chemoprevention}

\section{Myoinositol}

Myoinositol is a glucose isomer derived from grains, seed, and fruit. It is a precursor of several second messengers including diacylglycerol, which regulates some members of the protein kinase C family, inositol-1,4,5-triphosphate, which modifies intracellular calcium levels, and phosphatidylinositol-3,4,5biphosphate, which is involved in signal transduction. In a phase 1 study in smokers with bronchial dysplasia, myoinositol significantly increased the rate of regression of preexisting dysplastic lesions ( $91 \%$ vs $48 \%$; $P=0.014)$, using the regression rate of the placebo subjects from another recently completed clinical trial from the same investigators with the same inclusion/exclusion criteria as a comparison [54]. Myoinositol had also been reported to inhibit the PI3K pathway in vitro, and PI3K activity was found to be decreased in the airway of highrisk smokers who had significant regression of dysplasia after treatment with myoinositol [55]. In addition, myoinositol decreased endogenous and tobacco carcinogen-induced activation of Akt and ERK in immortalized human bronchial epithelial cells, which decreased cell proliferation and induced a G(1)-S cell cycle arrest. Significant decreases in Akt and ERK phosphorylation were observed in bronchial dysplastic lesions following myoinositol treatment in heavy smokers [56]. All of these findings support the ongoing phase 2 multicenter study sponsored by the NCI Mayo Clinic Cancer Prevention Network (ClinicalTrials.gov identifier: NCT00783705).

\section{PPAR-gamma agonist}

PPAR-gamma (PPAR- $\gamma$ ) is a nuclear hormone receptor that acts as a ligand-activated transcription factor and plays a pivotal role in regulating adipocyte differentiation, glucose and lipid homeostasis, and intracellular insulin-signaling events [57]. Transcriptional activities of PPAR- $\gamma$ are regulated by fatty acid binding. PPAR- $\gamma$ has been receiving growing interest for its involvement in carcinogenesis. Ligands of PPAR- $\gamma$ induced differentiation and apoptosis by NSCLC [58]. Reduced PPAR- $\gamma$ expression within the tumor is associated with poor prognosis in lung cancer patients. Synthetic PPAR- $\gamma$ agonists such as the thiazolidinedione (TZD) class of anti-diabetic drugs can inhibit growth of NSCLC cells in vitro, and block tumor progression in xenograft models [59]. Preclinical studies in NSCLC, colon, and prostate cancer cell lines have also implicated the involvement of PPAR- $\gamma$ in mediating apoptosis with 15-HETE, an AA metabolite of 15-lipoxygenase (15-LOX). PPAR- $\gamma$ agonists have been demonstrated to exhibit anticancer properties in colon, breast, and prostate cells [60-62]. Furthermore, the reductions of 15LOX, 15-HETE, and PPAR- $\gamma$ activity have been shown to contribute to lung carcinogenesis [63]. Recent reports of lung, prostate, and colon cancer rates in diabetic veterans receiving PPAR- $\gamma$ agonists revealed a 33\% decrease in lung cancer incidence compared to none users [64], suggesting that PPAR$\gamma$ activation may be useful in lung cancer chemoprevention. A phase 2 RCT using the PPAR- $\gamma$ agonist pioglitazone is actively recruiting subjects. Subjects will have quantitative highresolution thoracic $\mathrm{CT}$ scan and a fluorescent bronchoscopy at 
study entry and after 6 months on drug or placebo. The primary outcome is endobronchial histology and determining if pioglitazone can retard progression. Secondary end points related to the PPAR- $\gamma$ signaling pathway will also be analyzed (ClinicalTrials.gov identifier: NCT00780234).

Other agents of interest

\section{Tea extracts}

Many epidemiological studies and laboratory experiments suggest that tea consumption protects against chronic diseases, such as cardiovascular disease and cancer [65-67]. Tea contains high levels of flavonoids, including catechins and other polyphenols. These phytochemicals are thought to play key roles in mechanisms that may provide health benefits [68-71]. Through these mechanisms, tea has demonstrated significant antineoplastic effects in animal models of lung, skin, esophageal, and gastrointestinal cancers [72-74]. For example, green tea has been shown to inhibit lung tumor development in A/J mice treated with 4-(methylnitrosamino)-1-(3-pyridyl)-1-butanone (NNK), a potent lung carcinogen found in tobacco [75]. Green tea and EGCG has also been shown to inhibit breast and lung cancer in murine xenografts $[24,76]$. The potential of GTE for lung cancer chemoprevention is being evaluated in a phase 2 $\mathrm{RCT}$, the results of which are pending (ClinicalTrials.gov identifier: NCT00363805; NCT00573885).

Whereas the majority of the work evaluating the antineoplastic effects of tea has been done on green tea, the potential health benefits of white tea and its advantage over green tea are becoming increasingly recognized. In a recent report, our group reported that white tea extract (WTE) was more efficacious than green tea extract (GTE) in the induction of apoptosis in NSCLC cell lines, through the upregulation of 15-LOX, 15-HETE, and PPAR- $\gamma$, supporting further evaluation of the potential of WTE for lung chemoprevention in future clinical trials [77].

\section{Isothiocyanates}

Isothiocyanates, such as phenethyl isothiocyanate (PEITC) and sulforaphane, have been shown to inhibit carcinogenesis and are potential chemopreventive agents [78]. They have been shown to inhibit carcinogenesis through inhibition of cytochrome P450 enzymes, which oxidize compounds such as benzo $[a]$ pyrene and other polycyclic aromatic hydrocarbons (PAHs) into more polar epoxy-diols. These compounds can then cause mutation and induce cancer development. A randomized trial evaluating PEITC as a modifier of nicotinederived nitrosamine ketone (NNK) metabolism in smokers is currently recruiting subjects (ClinicalTrials.gov identifier: NCT00691132).
Other modulators of the arachidonic acid pathway

RCTs involving the 5-lipoxygenase inhibitor zileuton (ClinicalTrials.gov identifier: NCT00056004) and the NSAID sulindac, a nonspecific COX inhibitor, were conducted recently, pending publication of results (ClinicalTrials.gov identifier: NCT00368927). A recent meta-analysis of eight RCTs of daily aspirin to reduce the risk of vascular disease found a $20 \%-30 \%$ reduction in lung cancer mortality in people taking daily aspirin for 5 or more years [79•].

\section{Organosulfurs}

Oltipraz and anethole dithiolethione (ADT) are two organosulfur compounds belonging to the dithiolethione class. Oltipraz was studied in a phase I lung cancer chemoprevention trial with early termination due to hepato-toxicity [80, 81]. ADT is available in Europe and Canada for the treatment of xerostomia due to radiation. A phase IIb trial with ADT in smokers with bronchial dysplasia was performed in 2002. The progression rate of pre-existing dysplastic lesions by two or more grades and/or the appearance of new lesions was statistically significantly lower in the ADT group than the placebo group in both the person-specific (32\% versus $59 \%$ ) and lesion specific analysis (8\% versus $17 \%$ ) [82]. However, due to undesirable side effects of abdominal bloating and flatulence, a phase III trial of ADT was not conducted.

\section{Protein kinase C inhibitor}

In lung cancer cells, enzastaurin, a protein kinase C-â (PKCâ) inhibitor, had demonstrated inhibitory activity on intracellular signaling proteins [83]. Enzastaurin, had being studied in a phase IIb lung cancer chemoprevention trial in former smokers, result of which is pending (ClinicalTrials. gov identifier: NCT00414960).

\section{Future directions}

Due to a variety of social and political factors, support for lung cancer research pales in comparison with other common epithelial cancers. The dismal prognosis and disappointing results from previous screening trials with chest $\mathrm{x}$-ray and chemoprevention studies have also discouraged many talented individuals from pursuing a career in the field. As a result, progress in lung cancer research and management has generally lagged behind other common solid cancers. While the focus on smoking prevention and cessation should be maintained and intensified, efforts on exploring new frontiers for research and clinical management deserve equal emphasis, without which advancement and innovations will be 
impossible. With developing countries contributing to much of the tobacco epidemics, the global burden of lung cancer will continue to escalate for decades to come; such an epidemiologic transition in the Western society is now predictably occurring at an accelerated pace in the developing world. The magnitude of the problem underscores the urgency for the development of innovative chemopreventive strategies.

Inventive trials methods, such as adaptive design, marker assessment, and data analysis, should be employed in earlyphase clinical studies. For the detection of central precursor lesions, better imaging techniques including noninvasive methods to detect and follow endobronchial premalignancy, such as autofluorescence-guided optical coherence tomography (OCT), may help bypass the potential sampling issue associated with biopsy, allowing for more accurate assessment of the natural history and effects of chemoprevention on these lesions [84]. For detection of small peripheral lesions, the development of molecular imaging coupled with the target of interest, such as COX-2-targeted imaging using positron emission tomography (PET) or single photon emission computed tomography (SPECT) tracers, promises the potential of detecting COX-2-expressing lesions and enhances predictive information for responsiveness to $\mathrm{COX}-2$ inhibitors [85-87].

The use of a sophisticated model system for end point analysis, such as mixed effect model analysis in our celecoxib trial, clearly demonstrates that the higher the baseline Ki-67 LI, the more likely a treatment response is observed. The association of Ki-67 responders having higher BAL cell COX-2/15-PGDH than non-responders also presents a new direction for a more focused trial design in the future with celecoxib-for instance, restricting inclusion of subjects to those with elevated baseline bronchial Ki-67 LI and BAL cell COX-2/15-PGDH. An elevated baseline bronchial proliferative index should reflect a stronger driving force of cancerization in the lung microenvironment or higher risk for lung cancer at the molecular level, whereas an elevated BAL cell COX-2/15-PGDH may increase the likelihood of responding to COX-2 inhibition [27•].

The lack of validated SEBM for early-phase lung cancer chemoprevention trials continues to curtail progress in the field. Studies of typical phase 2 SEBM such as histopathology and Ki-67 will need to be validated within the context of phase 3 cancer end point trials [88]. In view of the complexity of lung cancer biology, favorable alterations in a combination of biomarkers rather than in any single biomarker will be required to achieve the level of sensitivity and specificity adequate for routine screening and therapeutic monitoring. To this end, application of system biology combining clinical characteristics, cellular and molecular phenotype derived from high-throughput technology such as gene expression profile, epigenetic alterations (methylation patterns and microRNA expression), proteomics and metabolomics, will allow more refined risk assessment, development of prediction model, and personalized approach to intervention to maximize efficacy and minimize treatment-related risks.

In line with these ideas, Gold and colleagues proposed another approach, "reverse migration," to accelerate the development of chemopreventive agents. This approach involves importing agents, targets, and study designs to personalize interventions developed in advanced cancer to cancer prevention - for example, using the model from the Biomarker-Integrated Approaches of Targeted Therapy for Lung Cancer Elimination (BATTLE) trial of personalized lung cancer therapy for personalized lung cancer prevention [89•]. BATTLE is the first completed prospective, biopsymandated, biomarker-based, adaptively randomized study in 255 pretreated lung cancer patients. Following an initial equal randomization period, chemo-refractory NSCLC patients were adaptively randomized to erlotinib, vandetanib, erlotinib plus bexarotene, or sorafenib, based on relevant molecular biomarkers analyzed in fresh core needle biopsy specimens. Overall results include a $46 \%$ 8-week disease control rate (primary end point), confirm prespecified hypotheses, and show an impressive benefit from sorafenib among mutant-KRAS patients. BATTLE establishes the feasibility of a new paradigm for a personalized approach to lung cancer clinical trials (Kim, ClinicalTrials.gov numbers: NCT00409968, NCT00411671, NCT00411632, NCT00410059, and NCT00410189). Development of this approach in tertiary prevention of second primary lung cancer with the above targeted agents will be the first logical step [90].

Analogous to treatment of other chronic noncommunicable diseases such as diabetes, the use of combination chemopreventive regimen with agents targeting various known carcinogenic pathways may prove to be more advantageous than a single agent, and allow the use of smaller doses to achieve synergy, minimize side effects, and sustain longterm benefits. Development of appropriate inhalational agents may also reduce the chance for systemic toxicity, although adherence with treatment, including the proper use of inhalational techniques, may interfere with consistent drug delivery to the lungs and efficacy. Exploration of old drugs with established track record of tolerability, such as metformin, which has been shown to inhibit cellular growth and proliferation, is also of future interest [91-93]. Table 2 lists potential molecular targets for lung cancer chemoprevention.

The success of the iloprost study helps illustrate the importance of collaborative efforts from lead investigators with expertise in specialized areas of translational research. Forging alliances by cooperative trial groups with synergistic programmatic approaches can overcome the challenges with recruitment, and improve and accelerate the development of the next generation of translational research approaches to lung cancer chemoprevention. 
Table 2 Molecular targets for lung cancer chemoprevention

Potential molecular targets for lung cancer chemoprevention

COX-2
PGI $_{2}$
PPAR-gamma
PI3K
mTOR
5-LOX
15-LOX
EGFR
Tyrosine kinase
Methylation
Angiogenesis
Histone deacetylase

\section{Conclusions}

Despite decades of disappointment, the invaluable lessons we learned from past failures have established the path toward success. Recognizing the power of prevention and early detection, future studies will continue to build upon prior experiences. In view of the complexity of the pathogenesis of lung cancer, biomarker-driven approaches based on sound understanding of clinical tumor biology, combined with advanced diagnostic technology and systematic application of bioinformatics, promise to propel progress in the field. With dedication, creativity, open-mindedness, hard work, and perseverance, the development of practical, personalized paradigms for lung cancer chemoprevention is well within reach and will soon become a reality.

Disclosure No potential conflicts of interest relevant to this article were reported.

\section{References}

Papers of particular interest, published recently, have been highlighted as:

\section{- Of importance}

1. "Nicotine: A Powerful Addiction." Centers for Disease Control and Prevention

2. American Caner Society. Cancer facts and figures 2008. Atlanta: American Cancer Society; 2008.

3. WHO World Cancer Report 2008

4. Bach PB, Kattan MW, Thornquist MD, Kris MG, Tate RC, Barnett $\mathrm{MJ}$, et al. Variations in lung cancer risk among smokers. J Natl Cancer Inst. 2003;95:470-9.

5. Peto R, Darby S, Deo H, Silcocks P, Whitley E, Doll R. Smoking, smoking cessation, and lung cancer in the UK since 1950: combination of national statistics with two case-control studies. BMJ. 2000;321:323-9.

6. Godrfredsen NS, Prescott E, Osler M. Effect of smoking reduction on lung cancer risk. JAMA. 2005;294:1505-10.
7. Sporn MB, Dunlop NM, Newton DL, Smith JM. Prevention of chemical carcinogenesis by vitamin A and its synthetic analogs (retinoids). Fed Proc. 1976;35(6):1332-8.

8. Kinsinger L, Harris R, Lewis C, Wooddell M. Chemoprevention of Breast Cancer [Internet]. Rockville (MD): Agency for Healthcare Research and Quality (US); 2002 Jul. Available from http://www. ncbi.nlm.nih.gov/bookshelf/br.fcgi?book=es8

9. Thompson IM, Goodman PJ, Tangen CM, Lucia MS, Miller GJ, Ford LG, Lieber MM, Cespedes RD, Atkins JN, Lippman SM, Carlin SM, Ryan A, Szczepanek CM, Crowley JJ, Coltman Jr CA. The influence of finasteride on the development of prostate cancer. N Engl J Med. 2003;349(3):215-24.

10. Steinbach G, Lynch PM, Phillips RK, Wallace MH, Hawk E, Gordon GB, Wakabayashi N, Saunders B, Shen Y, Fujimura T, et al. The effect of celecoxib, a cyclooxygenase-2 inhibitor, in familial adenomatous polyposis. N Engl J Med. 2000;342:1946-52.

11. Bertagnolli MM, Eagle CJ, Zauber AG, Redston M, Solomon SD, Kim K, Tang J, Rosenstein RB, Wittes J, Corle D, Hess TM, Woloj GM, Boisserie F, Anderson WF, Viner JL, Bagheri D, Burn J, Chung DC, Dewar T, Foley TR, Hoffman N, Macrae F, Pruitt RE, Saltzman JR, Salzberg B, Sylwestrowicz T, Gordon GB, Hawk ET. APC Study Investigators. Celecoxib for the prevention of sporadic colorectal adenomas. N Engl J Med. 2006;355(9):87384.

12. The Alpha-Tocopherol, Beta Carotene Cancer Prevention Study Group. The effect of vitamin $\mathrm{E}$ and beta carotene on the incidence of lung cancer and other cancers in male smokers. N Engl J Med. 1994;330:1029-35.

13. Hennekens CH, Buring JE, Manson JE, Stampfer M, Rosner B, Cook NR, Belanger C, LaMotte F, Gaziano JM, Ridker PM, et al. Lack of effect of long-term supplementation with beta carotene on the incidence of malignant neoplasms and cardiovascular disease. N Engl J Med. 1996;334:1145-9.

14. Lippman SM, Lee JJ, Karp DD, Vokes EE, Benner SE, Goodman GE, Khuri FR, Marks R, Winn RJ, Fry W, Graziano SL, Gandara DR, Okawara G, Woodhouse CL, Williams B, Perez C, Kim HW, Lotan R, Roth JA, Hong WK. Randomized phase III intergroup trial of isotretinoin to prevent second primary tumors in stage I non-small-cell lung cancer. J Natl Cancer Inst. 2001;93(8):605-18.

15. Omenn GS. Chemoprevention of lung cancer: the rise and demise of beta-carotene. Annu Rev Public Health. 1998;19:73-99.

16. van Zandwijk N, Dalesio O, Pastorino U, de Vries N, van Tinteren H. EUROSCAN, a randomized trial of vitamin A and $\mathrm{N}$-acetylcysteine in patients with head and neck cancer or lung cancer. For the EUropean Organization for Research and Treatment of Cancer Head and Neck and Lung Cancer Cooperative Groups. J Natl Cancer Inst. 2000;92:977-86.

17. Kamangar F, Qiao YL, Yu B, Sun XD, Abnet CC, Fan JH, Mark SD, Zhao P, Dawsey SM, Taylor PR. Lung cancer chemoprevention: a randomized, double-blind trial in Linxian, China. Cancer Epidemiol Biomarkers Prev. 2006;15(8):1562-4.

18. Karp DD, Lee SJ, Shaw Wright GL, Johnson DH, Johnson MR, Goodman GE, et al. MDACC Thoracic Chemoprevention Research Group. A phase III, intergroup, randomized, double-blind, chemoprevention trial of selenium (Se) supplementation in resected stage I non-small cell lung cancer (NSCLC). Proceedings of ASCO 2010;28abs CRA7004.

19. Lippman SM, Benner SE, Hong WK. Cancer chemoprevention. J Clin Oncol. 1994;12(4):851-73. Review.

20. Slaughter DP, Southwick HW, Smejkal W. Field cancerization in oral stratified squamous epithelium; clinical implications of multicentric origin. Cancer. 1953;6(5):963-8.

21. Hirsch FR, Franklin WA, Gazdar AF, Bunn Jr PA. Early detection of lung cancer:clinical perspectives of recent advances in biology and radiology. Clin Cancer Res. 2001;7(1):522. Review. 
22. Khuri FR. The dawn of a revolution in personalized lung cancer prevention. Cancer Prev Res (Phila). 2011;4(7):949-53.

23. Keith RL. Chemoprevention of lung cancer. Proc Am Thorac Soc. 2009;6(2):187-93. Review.

24. Li GX, Chen YK, Hou Z, Xiao H, Jin H, Lu G, Lee MJ, Liu B, Guan F, Yang Z, Yu A, Yang CS. Pro-oxidative activities and doseresponse relationship of(-)-epigallocatechin-3-gallate in the inhibition of lung cancer cell growth: a comparative study in vivo and in vitro. Carcinogenesis. 2010;31(5):902-10.

25. Wattenberg LW, Wiedmann TS, Estensen RD, Zimmerman CL, Steele VE, Kelloff GJ. Chemoprevention of pulmonary carcinogenesis by aerosolized budesonide in female A/J mice. Cancer Res. 1997;57:5489-92.

26. Lam S, leRiche JC, McWilliams A, MacAulay C, Dyachkova Y, Szabo E, Mayo J, Schellenberg R, Coldman A, Hawk E, et al. A randomized phase IIb trial of pulmicort turbuhaler (budesonide) in people with dysplasia of the bronchial epithelium. Clin Cancer Res. 2004;10:6502-11.

27. • Mao JT, Roth MD, Fishbein MC, Aberle DR, Zhang ZF, Rao JY, Tashkin DP, Goodglick L, Holmes EC, Cameron RB, Dubinett SM, Elashoff R, Szabo E, Elashoff D. Lung cancer chemoprevention with celecoxib in former smokers. Cancer Prev Res (Phila). 2011;4(7):984-93. This is the second phase 2b RCT with celecoxib, involving exclusively former smokers, showing a positive primary end point-reduction of bronchial Ki-67 LI and favorable modulations of a number of secondary SEBM. Results from the study also implicate the baseline ratio of $C O X-2$ to 15-hydroxyprostaglandin dehydrogenase (15-PGDH) $m R N A$ in BAL cells as a predictive marker of Ki-67 response to celecoxib, suggesting the potential of these biomarkers for personalizing chemopreventive strategies. The reduction of Ki-67 LI correlated with a reduction and/or resolution of lung nodules on chest CT, suggesting that the systemic administration of celecoxib is biologically active both in the central bronchi and in the periphery of the lungs.

28. Lee JJ, Liu D, Lee JS, Kurie JM, Khuri FR, Ibarguen H, Morice RC, Walsh G, Ro JY, Broxson A, Hong WK, Hittelman WN. Long-term impact of smoking on lung epithelial proliferation in current and former smokers. J Natl Cancer Inst. 2001;93 (14):1081-8.

29. Martin B, Paesmans M, Mascaux C, Berghmans T, Lothaire P, Meert AP, Lafitte JJ, Sculier JP. Ki-67 expression and patients survival in lung cancer: systematic review of the literature with meta-analysis. Br J Cancer. 2004;91(12):2018-25.

30. Barsky SH, Roth MD, Kleerup EC, Simmons M, Tashkin DP. Histopathologic and molecular alterations in bronchial epithelium in habitual smokers of marijuana, cocaine, and/or tobacco. J Natl Cancer Inst. 1998;90(16):1198-205.

31. Hittelman WN, Liu DD, Kurie JM, Lotan R, Lee JS, Khuri F, Ibarguen H, Morice RC, Walsh G, Roth JA, Minna J, Ro JY, Broxson A, Hong WK, Lee JJ. Proliferative changes in the bronchial epithelium of former smokers treated with retinoids. J Natl Cancer Inst. 2007;99(21):1603-12.

32. Veronesi G, Szabo E, Decensi A, Guerrieri-Gonzaga A, Bellomi M, Radice D, Ferretti S, Pelosi G, Lazzeroni M, Serrano D, Lippman SM, Spaggiari L, Nardi-Pantoli A, Harari S, Varricchio C, Bonanni B. Randomized phase II trial of inhaled budesonide versus placebo in high-risk individuals with CT screen-detected lung nodules. Cancer Prev Res (Phila). 2011;4(1):34-42.

33. Bresalier RS, Sandler RS, Quan H, Bolognese JA, Oxenius B, Horgan K, Lines C, Riddell R, Morton D, Lanas A, Konstam MA, Baron JA, for the Adenomatous Polyp Prevention on Vioxx (APPROVe) Trial Investigators. Cardiovascular events associated with rofecoxib in a colorectal adenoma chemoprevention trial. $\mathrm{N}$ Engl J Med. 2005;352:1092-102.

34. Solomon SD, McMurray JJ, Pfeffer MA, Wittes J, Fowler R, Finn P, Anderson WF, Zauber A, Hawk E, Bertagnolli M, for the
Adenoma Prevention with Celecoxib (APC) Study Investigators. Cardiovascular risk associated with celecoxib in a clinical trial for colorectal adenoma prevention. N Engl J Med. 2005;352: 1071-80.

35. Solomon SD, Wittes J, Finn PV, Fowler R, Viner J, Bertagnolli MM, Arber N, Levin B, Meinert CL, Martin B, Pater JL, Goss PE, Lance P, Obara S, Chew EY, Kim J, Arndt G, Hawk E, Cross Trial Safety Assessment Group. Cardiovascular risk of celecoxib in 6 randomized placebo-controlled trials: the cross trial safety analysis. Circulation. 2008;117(16):2104-13.

36. Kye SH, Tashkin DP, Roth MD, Adams B, Nie WX, Mao JT. Recruitment strategies for a lung cancer chemoprevention trial involving ex-smokers. Contemp Clin Trials. 2009;30:46472.

37. • Kim ES, Hong WK, Lee JJ, Mao L, Morice RC, Liu DD, Jimenez CA, Eapen GA, Lotan R, Tang X, Newman RA, Wistuba II, Kurie JM. Biological activity of celecoxib in the bronchial epithelium of current and former smokers. Cancer Prev Res (Phila). 2010;3 (2):148-59. This is the first RCT with celecoxib, showing a positive finding on the primary end point-reduction of bronchial Ki-67 LI after 3 months of treatment. The study also showed the importance of adequate dosing, as low dose was ineffective. In addition, subgroup analysis indicates that the effects are more pronounced in former smokers.

38. • Keith RL, Blatchford PJ, Kittelson J, Minna JD, Kelly K, Massion PP, Franklin WA, Mao J, Wilson DO, Merrick DT, Hirsch FR, Kennedy TC, Bunn PA Jr, Geraci MW, Miller YE. Oral iloprost improves endobronchial dysplasia in former smokers. Cancer Prev Res (Phila). 2011;4(6):793-802. This is a multi-center RCT evaluating a prostacyclin $\left(P_{G} I_{2}\right)$ analogue, iloprost, on former or current smokers with sputum atypia. Six months of iloprost significantly improved bronchial dysplasia, the primary end point. This is the first phase $2 b$ RCT study that has shown a positive finding in histopathology.

39. Menter DG, Schilsky RL, Dubois RN. Cyclooxygenase-2 and cancer treatement: understanding the risk should be worth the reward. Clin Cancer Res. 2010;5:1384-90.

40. Mao JT, Cui X, Reckamp K, Liu M, Krysan K, Dalwadi H, et al. Chemoprevention strategies with cyclooxygenase-2 inhibitors for lung cancer. Clin Lung Cancer. 2005;1:30-9.

41. Masferrer JL, Koki A, Seibert K. COX-2 inhibitors. A new class of antiangiogenic agents. Ann N Y Acad Sci. 2000;889:84 6.

42. Huang M, Stolina M, Sharma S, Mao J, Zhu L, Miller P, et al. Nonsmall cell lung cancer cyclooxygenase-2-dependent regulation of cytokine balance in lymphocytes and macrophages: up-regulation of interleukin 10 and down-regulation of interleukin 12 production. Cancer Res. 1998;58:1208-16.

43. Sugiura T, Ogawa M, Takahashi T. Cyclooxygenase-2 inhibitor induces apoptosis and enhances cytotoxicity of various anticancer agents in non-small cell lung cancer cell lines. Clin Cancer Res. 2000;6:2006-11.

44. Khuri FR, Wu H, Lee JJ, Kemp BL, Lotan R, Lippman SM, et al. Cyclooxygenase-2 overexpression is a marker of poor prognosis in stage I non-small cell lung cancer. Clin Cancer Res. 2001;7:861-7.

45. Rioux N, Castonguay A. Prevention of NNK-induced lung tumorigenesis in A/J mice by acetylsalicylic acid and NS-398. Cancer Res. 1998;58:5354-60.

46. Stolina M, Sharma S, Lin Y, Dohadwala M, Gardner B, Luo J, et al. Specific inhibition of cyclooxygenase 2 restores antitumor reactivity by altering the balance of IL-10 and IL-12 synthesis. J Immunol. 2000;164:361-70.

47. Mao JT, Roth MD, Serio KJ, Baratelli F, Zhu L, Holmes EC, et al. Celecoxib modulates the capacity for prostaglandin E2 and interleukin-10 production in alveolar macrophages from active smokers. Clin Cancer Res. 2003;9:5835-41. 
48. Mao JT, Fishbein MC, Adams B, Roth MD, Goodglick L, Hong L, et al. Celecoxib decreases Ki-67 proliferative index in active smokers. Clin Cancer Res. 2006;12:314-20.

49. Ding Y, Tong M, Liu S, Moscow JA, Tai HH. NAD+-linked 15hydroxyprostaglandin dehydrogenase (15-PGDH) behaves as a tumor suppressor in lung cancer. Carcinogenesis. 2005;26:65-72.

50. Veronesi G, Szabo E, Decensi A, Guerrieri-Gonzaga A, Bellomi M, Radice D, Ferretti S, Pelosi G, Lazzeroni M, Serrano D, Lippman SM, Spaggiari L, Nardi-Pantoli A, Harari S, Varricchio C, Bonanni B. Randomized phase II trial of inhaled budesonide versus placebo in high-risk individuals with CT screen-detected lung nodules. Cancer Prev Res (Phila). 2011;4(1):34 42.

51. Stearman RS, Dwyer-Nield L, Zerbe L, Blaine SA, Chan Z, Bunn Jr PA, Johnson GL, Hirsch FR, Merrick DT, Franklin WA, Baron AE, Keith RL, Nemenoff RA, Malkinson AM, Geraci MW. Analysis of orthologous gene expression between human pulmonary adenocarcinoma and a carcinogen-induced murine model. Am J Pathol. 2005;167(6):1763-75.

52. Heasley LE, Thaler S, Nicks M, Price B, Skorecki K, Nemenoff RA. Induction of cytosolic phospholipase A2 by oncogenic Ras in human non-small cell lung cancer. J Biol Chem. 1997;272:145014

53. Keith RL, Miller YE, Hoshikawa Y, Moore MD, Gesell TL, Gao $\mathrm{B}$, et al. Manipulation of pulmonary prostacyclin synthase expression prevents murine lung cancer. Cancer Res. 2002;62:734-40.

54. Lam S, McWilliams A, LeRiche J, MacAulay C, Wattenberg L, Szabo E. A phase I study of myo-inositol for lung cancer chemoprevention. Cancer Epidemiol Biomarkers Prev. 2006;15(8):152631

55. Gustafson AM, Soldi R, Anderlind C, Scholand MB, Qian J, Zhang X, Cooper K, Walker D, McWilliams A, Liu G, Szabo E, Brody J, Massion PP, Lenburg ME, Lam S, Bild AH, Spira A. Airway PI3K pathway activation is an early and reversible event in lung cancer development. Sci Transl Med. 2010;2(26):26ra25.

56. Han W, Gills JJ, Memmott RM, Lam S, Dennis PA. The chemopreventive agent myoinositol inhibits Akt and extracellular signal-regulated kinase in bronchial lesions from heavy smokers. Cancer Prev Res (Phila). 2009;2(4):370-6.

57. Kersten S, Desvergne B, Wahli W. Roles of PPARs in health and disease. Nature. 2000;405:421.

58. Chang TH, Szabo E. Induction of differentiation and apoptosis by ligands of peroxisome proliferators activated receptor $\gamma$ in non-small cell lung cancer. Cancer Res. 2000;60:1129-38.

59. Keshamouni VG, Reddy RC, Arenberg DA, Joel B, Thannickal VJ, Kalemkerian GP, Standiford TJ. Peroxisome proliferatoractivated receptor-gamma activation inhibits tumor progression in non-small-cell lung cancer. Oncogene. 2004;23(1):100-8.

60. Moreno JJ. New aspects of the role of hydroxyeicosatetraenoic acids in cell growth and cancer development. Biochem Pharmacol. 2009;77:1-10.

61. Shappell SB, Gupta RA, Manning S, Whitehead R, Boeglin WE, Schneider C, Case T, Price J, Jack GS, Wheeler TM, Matusik RJ, Brash AR, Dubois RN. 15S-Hydroxyeicosatetraenoic acid activates peroxisome proliferator-activated receptor gamma and inhibits proliferation in PC3 prostate carcinoma cells. Cancer Res. 2001;61 (2):497-503

62. Grommes C, Landreth GE, Heneka MT. Antineoplastic effects of peroxisome proliferator-activated receptor gamma agonists. Lancet Oncol. 2004;5(7):419-29. Review.

63. Yuan H, Li MY, Ma LT, et al. 15-Lipoxygenasesand its metabolites 15(S)-HETE and 13(S)-HODE in the development of non-small cell lung cancer. Thorax. 2010;65(4):321-6.

64. Govindarajan R, Ratnasinghe L, Simmons DL, Siegel ER, Midathada MV, Kim L, Kim PJ, Owens RJ, Lang NP. Thiazolidinediones and the risk of lung, prostate, and colon cancer in patients with diabetes. J Clin Oncol. 2007;25(12):1476-81.
65. Tijburg LB, Mattern T, Folts JD, Weisgerber UM, Katan MB. Tea flavonoids and cardiovascular disease: a review. Crit Rev Food Sci Nutr. 1997;37(8):771-85.

66. Dreosti IE. Antioxidant polyphenols in tea, cocoa, and wine. Nutrition. 2000;16(7-8):692-4. Review.

67. Dashwood RH. Early detection and prevention of colorectal cancer Oncol Rep. 1999;6(2):277-81.

68. Ahmed S, Rahman A, Hasnain A, Lalonde M, Goldberg VM, Haqqi TM. Green tea polyphenol epigallocatechin-3-gallate inhibits the IL-1 beta-induced activity and expression of cyclooxygenase-2 and nitric oxide synthase-2 in human chondrocytes. Free Radic Biol Med. 2002;33(8):1097-105.

69. Siddiqui IA, Adhami VM, Saleem M, Mukhtar H. Beneficial effects of tea and its polyphenols against prostate cancer. Mol Nutr Food Res. 2006;50(2):130-43. Review.

70. Luceri C, Caderni G, Sanna A, Dolara P. Red wine and black tea polyphenols modulate the expression of cycloxygenase-2, inducible nitric oxide synthase and glutathione-related enzymes in azoxymethane-induced f344 rat colon tumors. J Nutr. 2002;132 (6):1376-9.

71. Yuan JM, Gao YT, Yang CS, Yu MC. Urinary biomarkers of tea polyphenols and risk of colorectal cancer in the Shanghai Cohort Study. Int J Cancer. 2007;120(6):1344-50.

72. de Boer JG, Yang H, Holcroft J, Skov K. Chemoprotection against $\mathrm{N}$-nitrosomethylbenzylamine induced mutation in the rat esophagus. Nutr Cancer. 2004;50:168-73.

73. Dashwood WM, Orner GA, Dashwood RH. Inhibition of betacatenin/Tcf activity by white tea, green tea, and epigallocatechin-3gallate (EGCG): minor contribution of $\mathrm{H}(2) \mathrm{O}(2)$ at physiologically relevant EGCG concentrations. Biochem Biophys Res Commun. 2002;296:584-8.

74. Yang CS, Wang X, Lu G, Picinich SC. Cancer prevention by tea: animal studies, molecular mechanisms and human relevance. Nat Rev Cancer. 2009;9(6):429-39.

75. Chung FL, Morse MA, Eklind KI, Xu Y. Inhibition of tobaccospecific nitrosamine-induced lung tumorigenesis by compounds derived from cruciferous vegetables and green tea. Ann N Y Acad Sci. 1993;686:186-201. discussion 201-2.

76. Sartippour M, Heber D, Lu Q, Ma M, Go VL, Nguyen M. Green tea inhibits breast cancer growth and angiogenesis. Nut Cancer. 2001;40:149-56.

77. Mao JT, Nie WX, Tsu IH, Jin YS, Rao JY, Lu QY, Zhang ZF, Go VL, Serio KJ. White tea extract induces apoptosis in non-small cell lung cancer cells: the role of peroxisome proliferator-activated receptor-\{gamma\} and 15-lipoxygenases. Cancer Prev Res (Phila). 2010;3(9):1132-40.

78. Zhang Y, Kensler TW, Cho CG, et al. Anticarcinogenic activities of sulforaphane and structurally related synthetic norbornyl isothiocyanates. Proc Natl Acad Sci U S A. 1994;91:314750.

79. - Rothwell PM, Fowkes FG, Belch JF, Ogawa H, Warlow CP, Meade TW. Effect of daily aspirin on long-term risk of death due to cancer: analysis of individual patient data from randomised trials. Lancet 2011;377(9759):31-41. This is a meta-analysis of eight RCTbased trials of daily aspirin to reduce the risk of vascular disease, with findings of 20\%-30\% reduction in lung cancer mortality in people taking daily aspirin for 5 or more years, further supporting the role of COX inhibitors in lung cancer chemoprevention.

80. Kelley M, Folz RJ, Glaser EM, Herndon JE, Crowell JA, Perloff M, Santella R, Gerdman E, Becker R, Bergan RC. Phase 1 chemoprevention trial of oltipraz in smokers. Proc Am Soc Clin Oncol. 2003;22:92.

81. Pendyala L, Schwartz G, Bolanowska-Higdon W, et al. Phase I/ pharmacodynamic study of $\mathrm{N}$-acetylcysteine/oltipraz in smokers: early termination due to excessive toxicity. Cancer Epidemiol Biomarkers Prev. 2001;10:269-72. 
82. Lam S, MacAulay C, Le Riche JC, et al. A randomized phase IIb trial of anethole dithiolethione in smokers with bronchial dysplasia. J Natl Cancer Inst. 2002;94:1001-9.

83. Gescher A. Analogs of staurosporine: potential anticancer drugs? Gen Pharmacol. 1998;31(5):721-8.

84. Lam S, Standish B, Baldwin C, McWilliams A, leRiche J, Gazdar A, Vitkin AI, Yang V, Ikeda N, MacAulay C. In vivo optical coherence tomography imaging of preinvasive bronchial lesions. Clin Cancer Res. 2008;14(7):2006-11.

85. Uddin MJ, Crews BC, Ghebreselasie K, Huda I, Kingsley PJ, Ansari MS, Tantawy MN, Reese J, Marnett LJ. Fluorinated COX-2 inhibitors as agents in PET imaging of inflammation and cancer. Cancer Prev Res (Phila). 2011;4(10):153645 .

86. Uddin MJ, Crews BC, Ghebreselasie K, Tantawy MN, Marnett LJ. [I]-Celecoxib Analogues as SPECT Tracers of Cyclooxygenase-2 in Inflammation. ACS Med Chem Lett. 2011;2(2):160-4.

87. Uddin MJ, Crews BC, Blobaum AL, Kingsley PJ, Gorden DL, McIntyre JO, Matrisian LM, Subbaramaiah K, Dannenberg AJ, Piston DW, Marnett LJ. Selective visualization of cyclooxygenase-2 in inflammation and cancer by targeted fluorescent imaging agents. Cancer Res. 2010;70(9):3618-27.
88. Szabo E. Assessing efficacy in early phase cancer prevention clinical trials: the case of ki-67 in the lung. Cancer Prev Res. 2010;3:128-31.

89. • Gold KA, Kim ES, Lee JJ, Wistuba II, Farhangfar CJ, Hong WK. The BATTLE to personalize lung cancer prevention through reverse migration. Cancer Prev Res (Phila). 2011;4(7):962-72. This article proposes a new approach, "reverse migration," to accelerate the development of personalized chemopreventive agents; for example, applying the model used in the Biomarker-Integrated Approaches of Targeted Therapy for Lung Cancer Elimination (BATTLE) trial of personalized lung cancer therapy for personalized lung cancer prevention.

90. Kim ES, Herbst RS, Wistuba II, Lee JJ, Blumenschein Jr GR, Tsao A, et al. The BATTLE trial: personalizing therapy for lung cancer. Cancer Discovery. 2011;1:44-53.

91. Antonoff MB, D'Cunha J. Teaching an old drug new tricks: metformin as a targeted therapy for lung cancer. Autumn. 2010;22(3):195-6.

92. Memmott RM, Mercado JR, Maier CR, Kawabata S, Fox SD, Dennis PA. Metformin prevents tobacco carcinogen-induced lung tumorigenesis. Cancer Prev Res (Phila). 2010;3(9):1066-76.

93. Engelman JA, Cantley LC. Chemoprevention meets glucose control. Cancer Prev Res (Phila). 2010;3(9):1049-52. 